\title{
REVERSE VS. EFFECTIVE STRAIN IN THE RING-ROLLING OF SUPERALLOY 718
}

\author{
Jon Alkorta $^{1}$; Jose M. Martinez-Esnaola ${ }^{1}$; Isabel Gutierrez ${ }^{1}$; Doug Rawson ${ }^{2}$; Marco Verza ${ }^{2}$; \\ Samuele Reghellin²; Javier Gil Sevillano \\ ${ }^{1}$ CEIT and TECNUN, University of Navarra \\ Paseo Manuel de Lardizabal 15, 20018 San Sebastian, Spain \\ ${ }^{2}$ FORGITAL Italy SpA \\ Via G. Spezzapria 1, Seghe, 36010 Velo d'Astico, Italy
}

Keywords: Alloy 718, Modelling and simulation, Aerospace

\begin{abstract}
A good understanding of the thermomechanical history of the material during the ring-rolling of Superalloy 718 is the key for establishing the conditions adequate for processing aeronautical parts through this attractive route. With respect to the forging route, where the strain path is mainly unidirectional, in every ring-rolling revolution the part suffers two small strain increments where the deformation alternates from tangential to axial rolling. Here we present a finite element analysis of the ring-rolling operation of Superalloy 718 for a geometry and size typical of a low-pressure turbine part, focusing on the reverse vs. effective strains imparted in the operation and in the heterogeneity of their ratio in the section of the ring.
\end{abstract}

\section{Introduction}

A reliable ring-rolling-only route for manufacturing IN718 alloy rotating aero-engine disk offers an alternative to the close-die forging route with several advantages: it is a near-net-shape process, it does not require expensive tooling and, moreover, it seems to be the only possible forming operation for manufacturing very large diameter disks.

From the end-user point of view, the rolled-only disks shall comply with the microstructural and mechanical requirements currently demanded for close-die forged aero-engine disks. Development of an advanced predictive ring-rolling modelling tool is a pre-requisite for mastering the process.

With respect to the forging route, where the strain path is mainly unidirectional and the shape change is given in large increments, in ring-rolling the shape change consists of the accumulation of a big number of small strain increments. Furthermore, in every ring-rolling revolution the part suffers two small strain increments where the deformation alternates from tangential to axial rolling, the importance of such strain reversal in a revolution depending on the constraint imposed to the height of the ring in the axial direction by the conical rolls. Even in the absence of such constraint, the mere thinning of the ring wall by rolling between the axial driving roll and the axial mandrel implies that an important fraction of reversal strain component is associated to the equivalent strain of each rolling pass, because the relative redundant strain in a rolling pass increases as the rolling pass reduction decreases for a fixed geometry of the rolls [1]. This question may be important for both operation modelling and microstructural control, because strain-path changes (strain reversal is the most extreme form of strain-patch change) have significant effects on both the stress-strain behaviour of a material and its microstructural evolution [2-4]. 
There is no lack of papers dealing with the numerical simulation of the ring-rolling operation (e.g., [5-19]). Here we present a finite element analysis (FEM) of the ring-rolling operation of Superalloy 718 for a geometry and size typical of a low-pressure turbine part, focusing on the reverse vs. effective strains imparted in the operation and on the heterogeneity of their ratio in the section of the ring.

\section{Model and input parameters}

The geometrical data used in the simulations are given in Table 1. For speeding up the calculations, only the upper half of the ring and tools have been considered (figure 1). Indeed such symmetrization somewhat exaggerates the stability of the process making impossible the out-of-plane buckling failure of the ring, but such failure can only occur for operating conditions very far from the optimal ones. The guide rolls only move around the fixed hinge. Their motion is controlled automatically and depends on the current ring diameter as measured by the FE model.

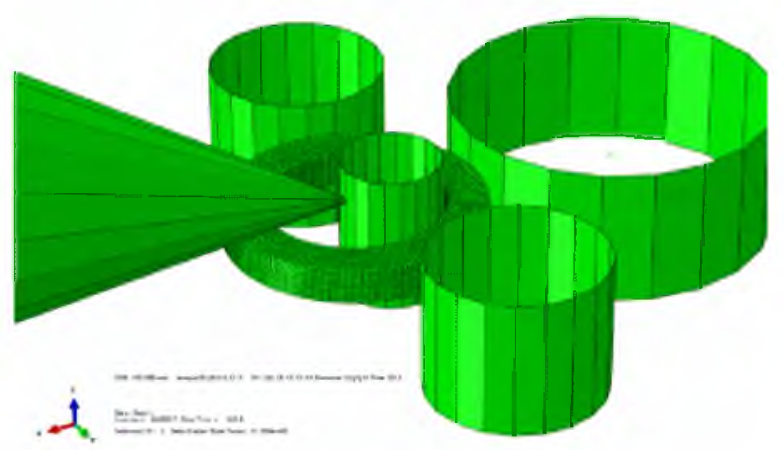

Figure 1. Configuration of the FEM rolling model during an internediate phase of the process.

Only the upper half of the ring and the upper conical roll are shown.

Table 1. Geometrical specifications of the model

\begin{tabular}{|l|c|}
\hline Initial external diameter of the ring & $720 \mathrm{~mm}$ \\
\hline Initial width of the ring & $185 \mathrm{~mm}$ \\
\hline Initial thickness of the ring & $244 \mathrm{~mm}$ \\
\hline Main roll rotational speed & $5 \mathrm{rpm}$ \\
\hline Nominal strain rate* & $0.003 \mathrm{~s}^{-1}$ \\
\hline
\end{tabular}

*The peaks of instantaneous strain rate may be orders of magnitude higher.

The upper half of the ring was discretized with C3D8RT elements with enhanced hourglass control (with second order accuracy) and arbitrary Lagrangian-Eulerian (ALE) adaptive meshing. The number of elements in the ring is $9600(8 \times 8 \times 150)$. We have used the commercial FEM code Abaqus/Explicit [20] with semi-automatic mass scaling (mass-scaling factor $=1000$ ).

Material properties have been obtained from experimental results obtained from a battery of isothermal unidirectional torsion tests at different temperatures and strain rates of samples machined from a cylinder of 718 alloy after upsetting by open forging in the same conditions intended for the industrial manufacture of the initial ring preform. The stress-strain behaviour was fitted using equation (1), as applied by Zhang et al. [21]. 


$$
\sigma=\sigma_{p}\left[\frac{\varepsilon}{\varepsilon_{p}} \exp \left(1-\frac{\varepsilon}{\varepsilon_{p}}\right)\right]^{0.1}
$$

$$
\begin{aligned}
& \sigma_{p}(M P a)=217 \operatorname{asinh}\left[\frac{1}{1.510^{23}} \varepsilon \exp \left(\frac{536750}{8.31 T}\right)\right]^{0227} \\
& \varepsilon_{p}=4.47 \times 10^{-4} D_{0}^{02005}\left[\varepsilon \exp \left(\frac{535750}{R T}\right)\right]^{-1054}
\end{aligned}
$$

A steady state has been assumed in the stress-strain curves when the flow stress attains $90 \%$ of the peak stress.

The assumed material starting temperature was $970^{\circ} \mathrm{C}$; a $60 \mathrm{~s}$ transfer time between the oven and the mill was assumed. Radiation plus convection heat losses were considered in all ring faces with exception of the inner one, where only radiation was taken into account. An emissivity coefficient of 0.85 was used, judged reasonable for the temperature range covered on the basis of bibliographic data [22]. For convection, a heat sink temperature of $25^{\circ} \mathrm{C}$ and a heat transfer coefficient of $30 \mathrm{~W} / \mathrm{Km}^{2}$ were selected. All other physical and thermal properties of the alloy have been taken from literature [23]. The axial conical rolls and the guiding rolls are assumed frictionless. The rotational speed of the driving roll and the mandrel displacement rate used in the simulations were located in an operation window that was a priori judged to be admissible from the point of view of the final microstructure, the admissible loads on the machine and the economy of the process (number of passes and intermediate reheatings).

\section{Results}

\section{$\underline{\text { Ring-rolling without axial constraint }}$}

The imparted strain is determined only by the rolling between the main driving roll and the moving mandrel. After $160 \mathrm{~s}$ of rolling (32 revolutions), the maps of equivalent strain (PEEQ) and temperature in the radial cross section of the ring are shown in fig. 2. The nominal equivalent deformation assuming plane strain would have been $\sim 0.48$; the heterogeneity of deformation is evident, as well as the redundancy of a fraction of the deformation. The average equivalent deformation in the section is well above the ideal figure. At a local level, this question of the redundant deformation fraction is better evidenced by plotting the map of another variable ( $P E M A G)$, sensitive to strain path changes, which is computed in a similar way as PEEQ, but considering the finite value of the plastic strain $\varepsilon_{i j}^{p l}$ at each final strain increment (instead of integrating $\dot{\varepsilon}_{\text {eq }}$ along the strain path). Thus, PEMAG would be identical to PEEQ for a monotonous strain path and zero for a cyclic deformation loop with no net shape change; it is a sort of "non-redundant equivalent strain". The results show that the strain path near the surface is mainly a cyclic path $(P E M A G<<P E E Q)$, similar to a low-cycle fatigue (LCF) experiment. On the other hand the strain path is practically monotonic in the inner part of the ring (PEEQ PEMAG). 

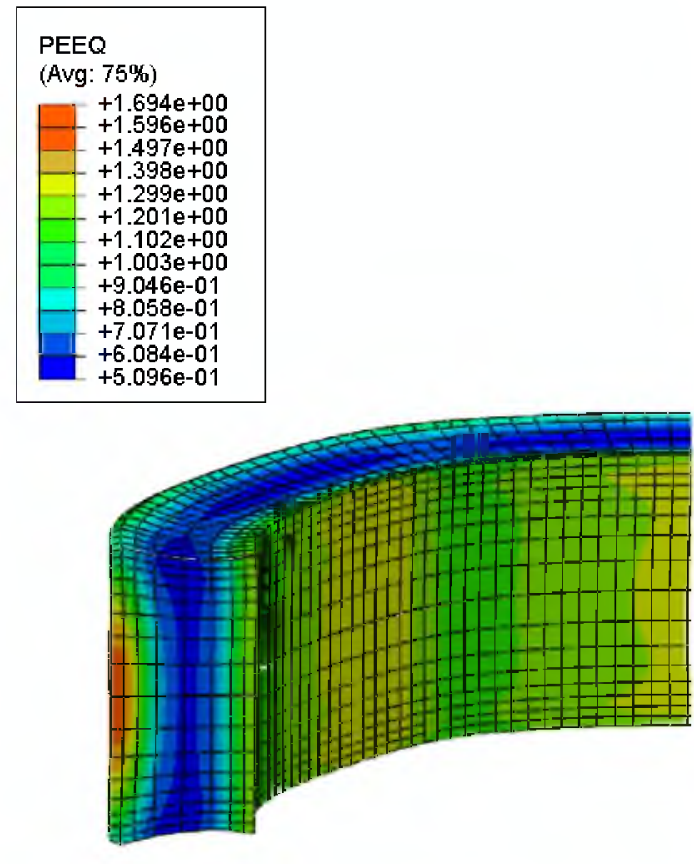

(a)
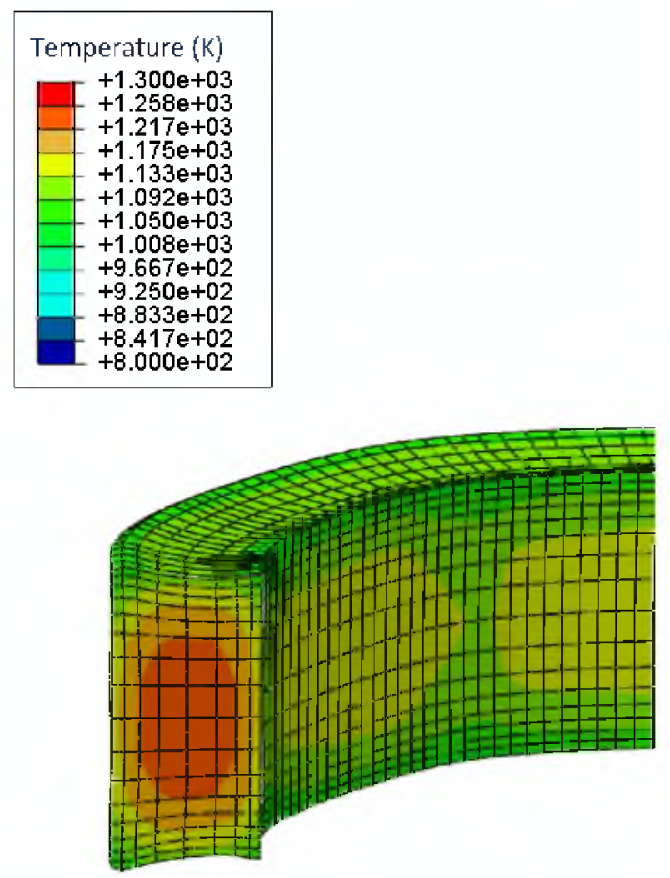

(b)

Figure 2. Ring-rolling with no axial constraint after $160 \mathrm{~s}$ of rolling (32 revolutions). Maps of a) equivalent plastic strain (PEEQ) and b) temperature (NT11), $\mathrm{K}$.

In fig. 3, the maps of the "non-redundant equivalent strain", $P E M A G$, and of the ratio of $P E M A G$ to PEEQ are plotted.

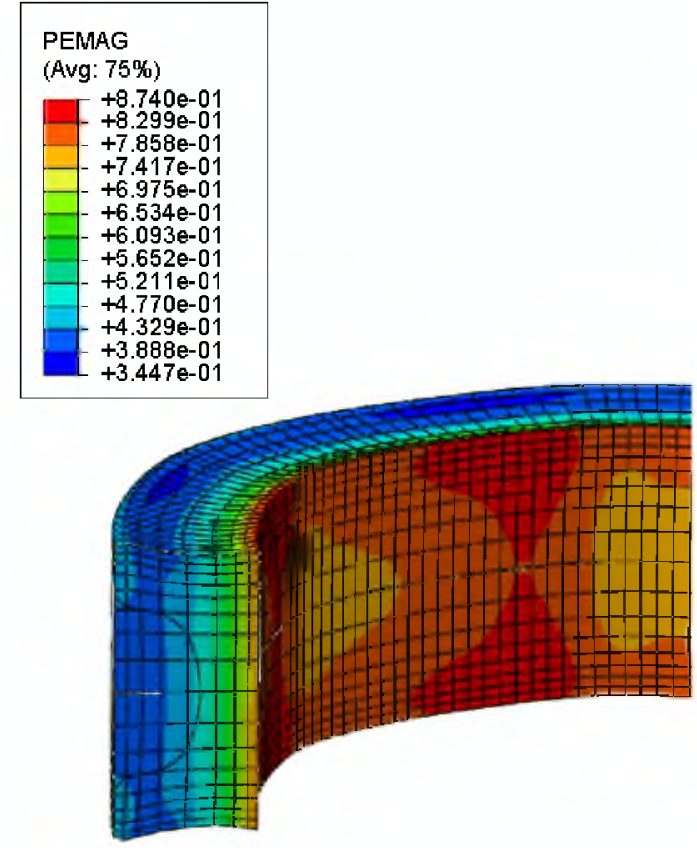

(a)

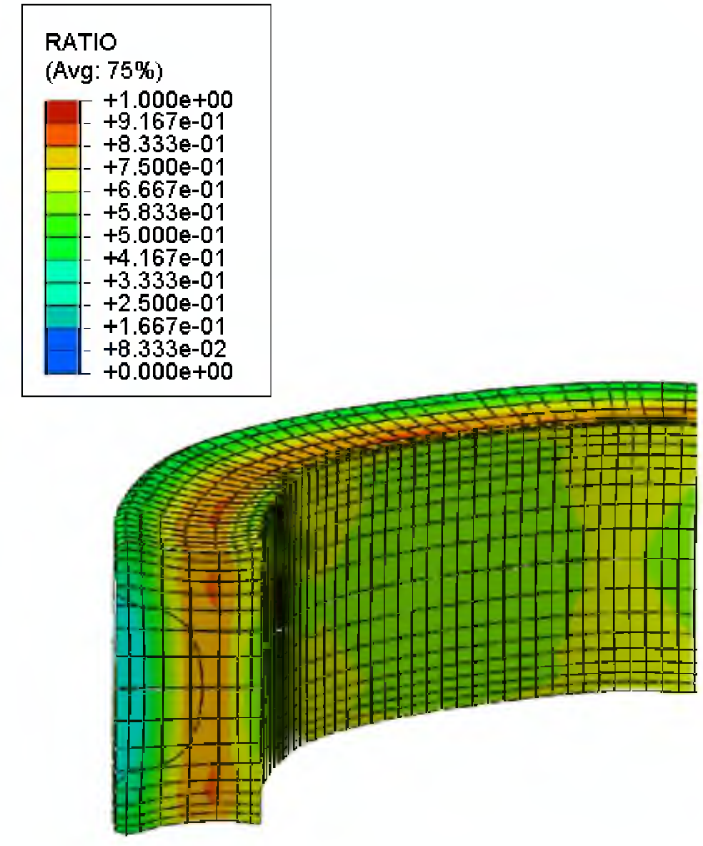

(b)

Figure 3. Ring-rolling with no axial constraint after $160 \mathrm{~s}$ of rolling (32 revolutions.). Maps of a) the "non-redundant equivalent strain" PEMAG and b) the ratio PEMAG/PEEQ. 
Several points in the radial section have been labelled as depicted in fig. 4a; the thermomechanical histories of two of them are shown in fig. 4(b). Notice the small plastic strain increment per pass, characteristic of ring-rolling. Obviously a modification of the mandrel displacement rate correspondingly changes the level of such increments and the strain rate, but at the price of increasing the force on the mandrel and the required torque to be applied to the driving roll.
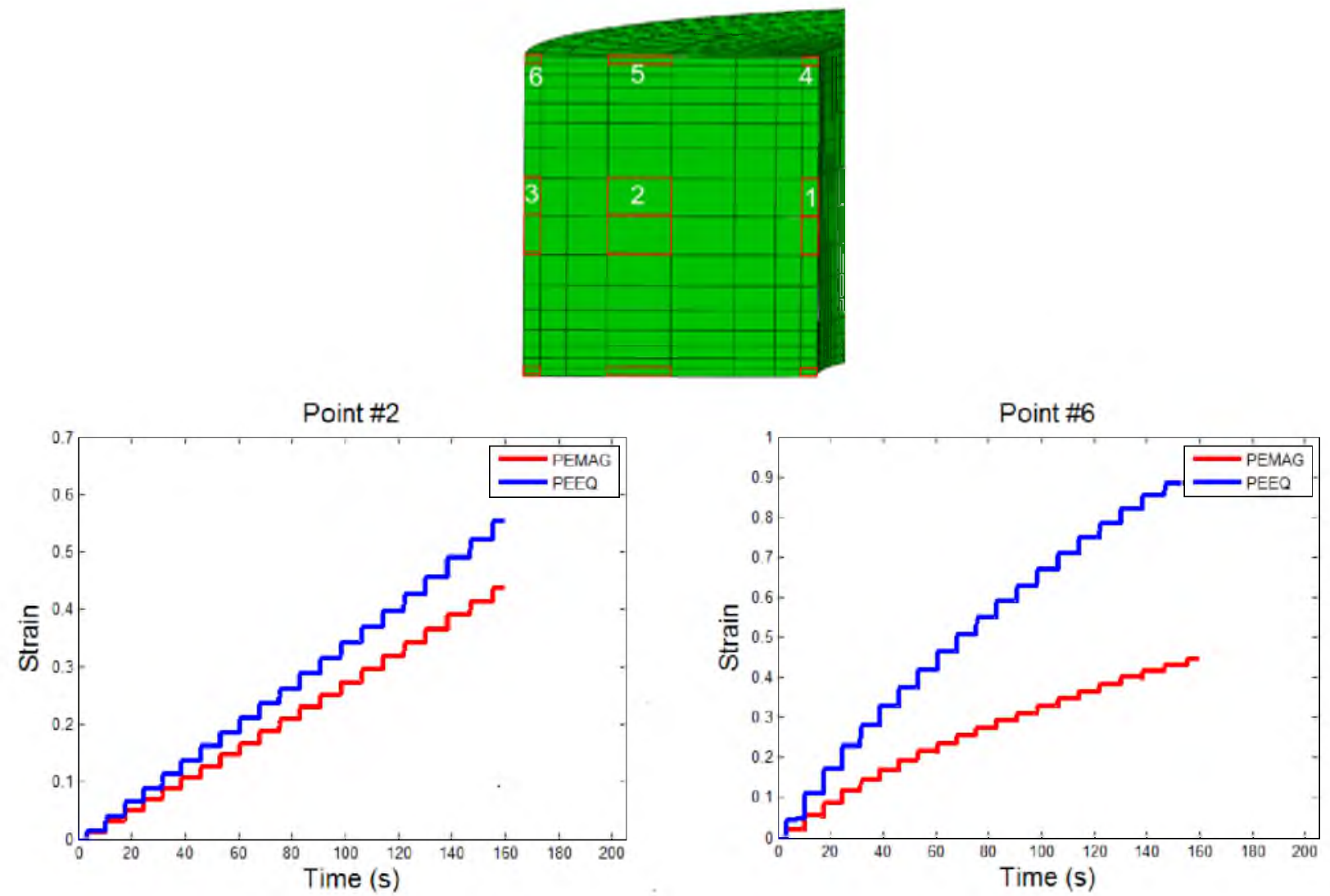

Figure 4. Ring-rolling with no axial constraint after $160 \mathrm{~s}$ of rolling (32 revolutions). Nomenclature of several points (centre of elements) in the radial section and evolution of equivalent strains $P E E Q$ and $P E M A G$ in points 2 and 6.

Figure 5 shows the temperature and PEMAG/PEEQ ratio profile along the diagonal of a cross section of the ring (i.e., owing to symmetry, along elements 6-2-4) at different rolling times (with its corresponding nominal strain level). The edges of the samples continuously cool down while the centre of the ring increases slightly its temperature due to quasi-adiabatic heating. The ratio PEMAG/PEEQ is lower at the edges of the ring but higher than 0.35 at any instant. 


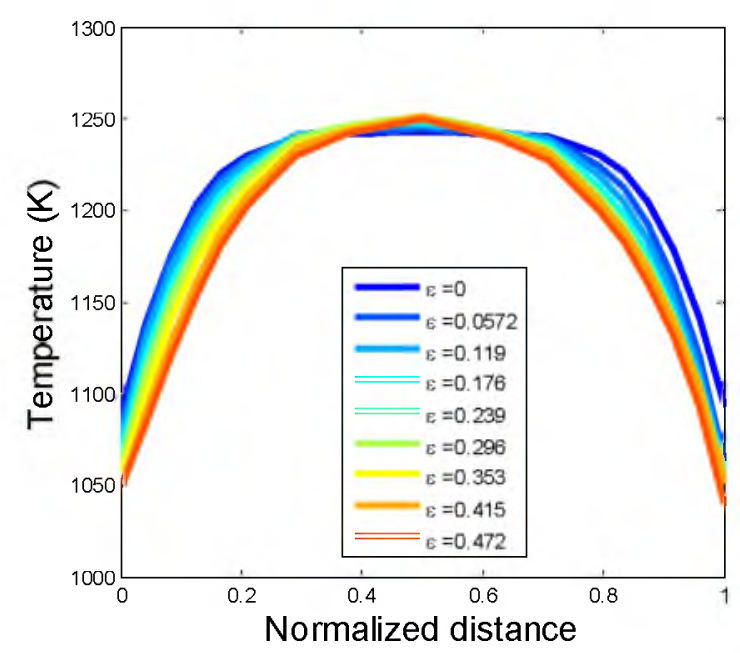

(a)

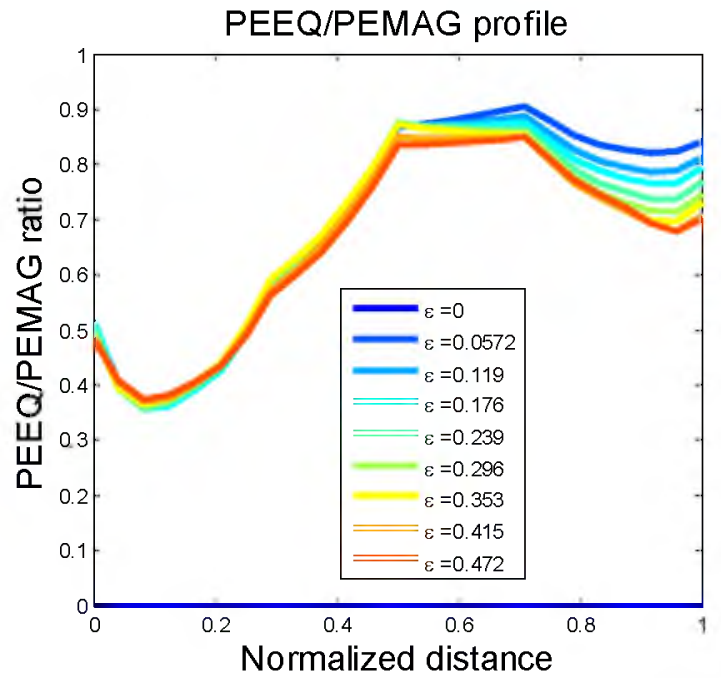

(b)

Figure 5. Ring-rolling with no axial constraint after $160 \mathrm{~s}$ of rolling (32 revolutions.). (a) Temperature profile $(\mathrm{K})$ along a diagonal of the ring section (distance convention: 0-upper corner, outer surface; 1-lower corner, inner surface). (b) Id., PEMAG/PEEQ ratio.

\section{$\underline{\text { Ring-rolling with fixed ring thickness }}$}

The axial constraint imposed by a fixed separation of the conical rolls introduces important changes in the results of the process. Figures 6 to 9 are to be compared with the previous figs. 2 to 5 .

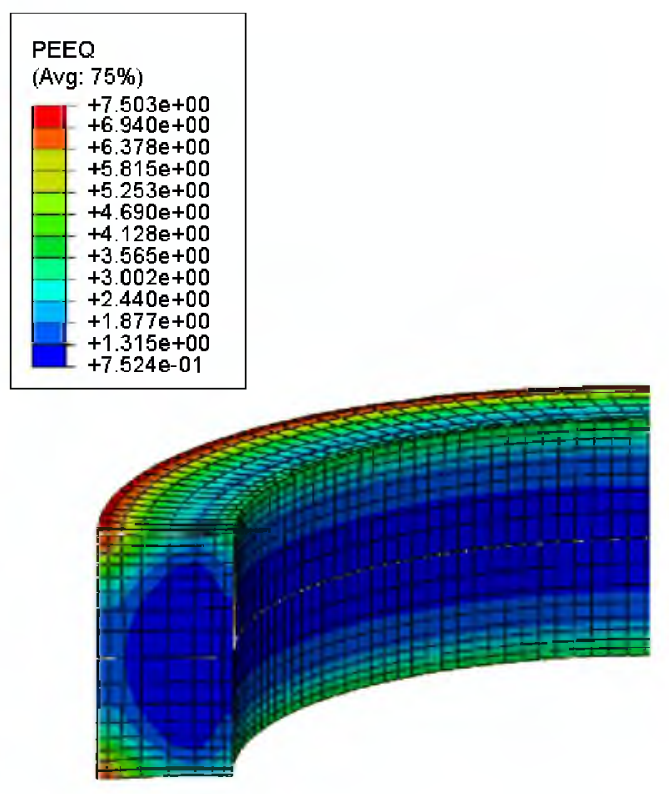

(a)
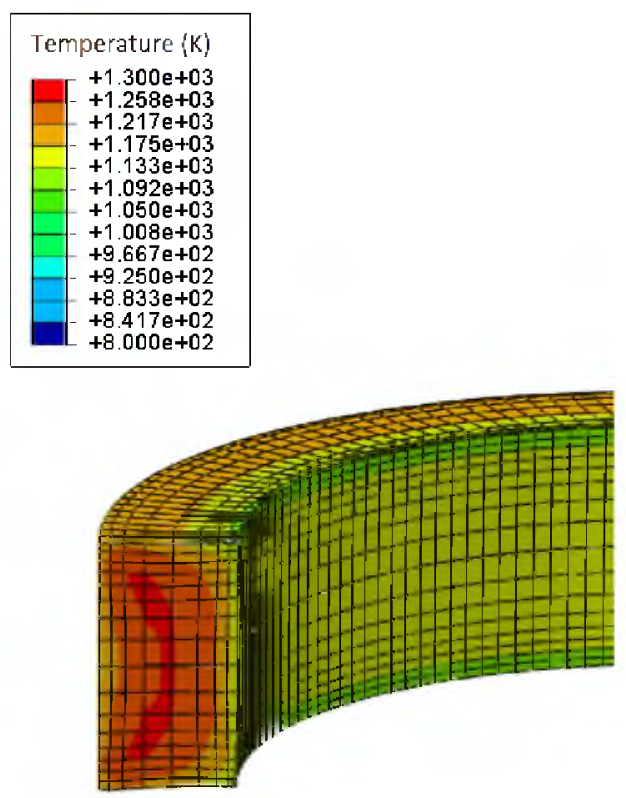

(b)

Figure 6. Ring-rolling with fixed thickness after $160 \mathrm{~s}$ of rolling (32 revolutions.). Maps of a) equivalent plastic strain (PEEQ) and b) temperature (NT11), K. 


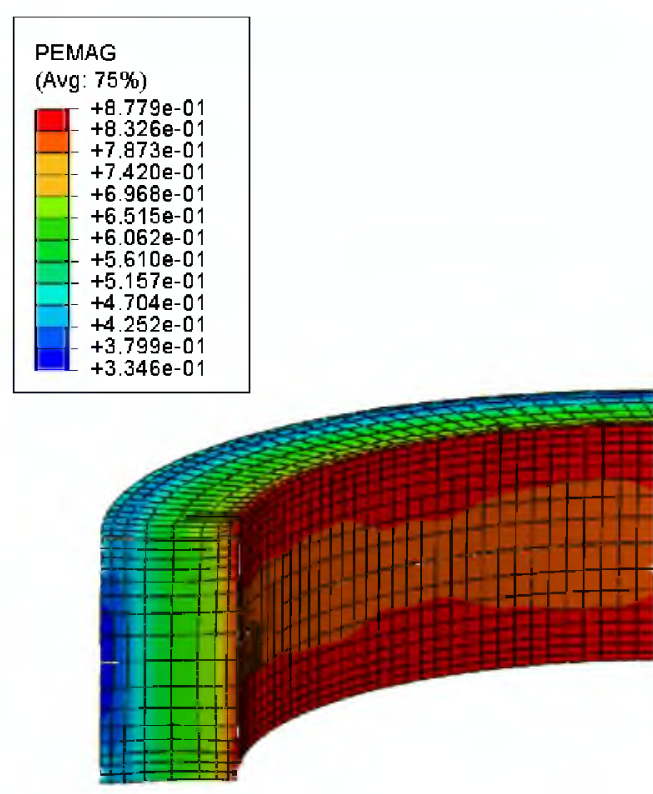

(a)

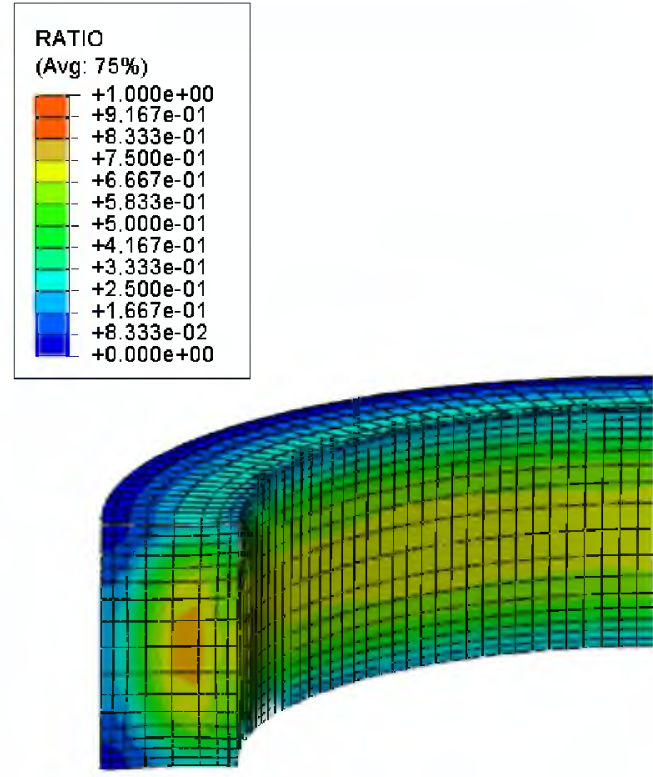

(b)

Figure 7. Ring-rolling with fixed thickness after $160 \mathrm{~s}$ of rolling (32 revolutions.). Maps of a) the "non-redundant equivalent strain" PEMAG and b) the ratio PEMAG/PEEQ.
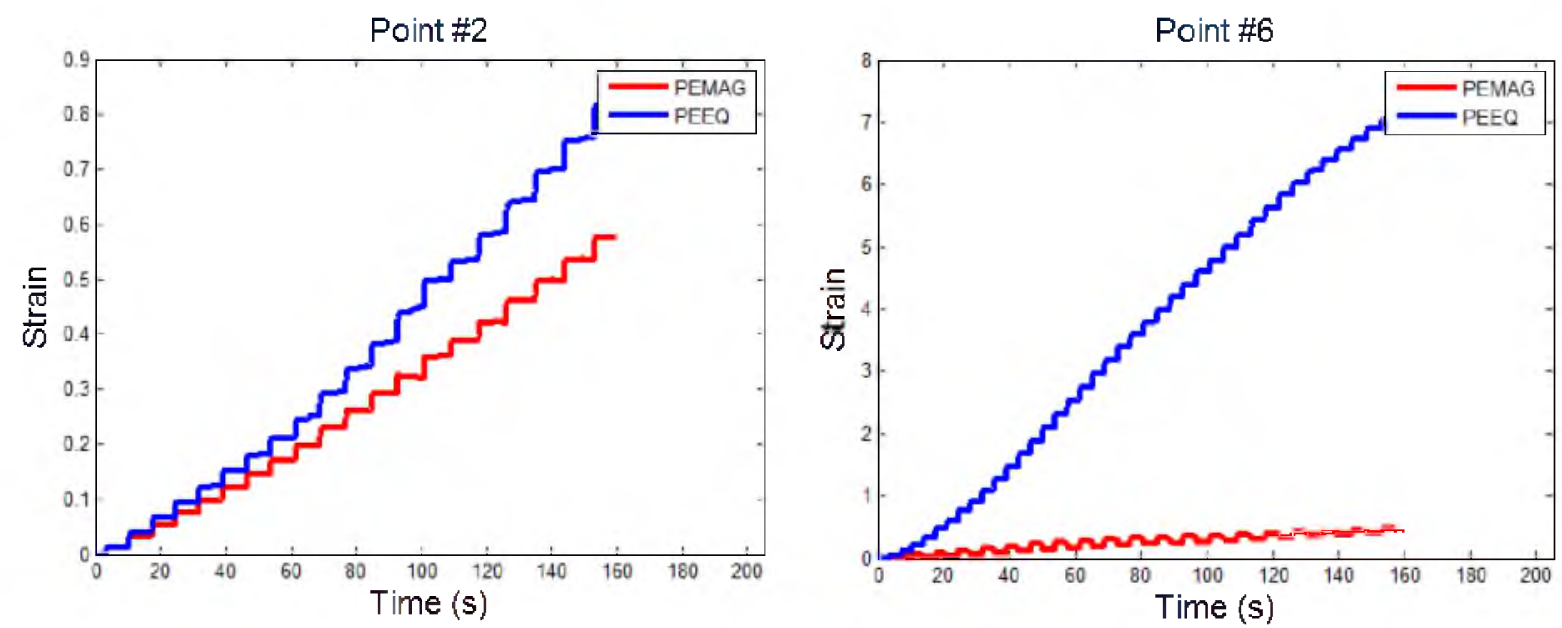

Figure 8. Ring-rolling with fixed thickness after $160 \mathrm{~s}$ of rolling ( 32 revolutions.). Evolution of equivalent strains $P E E Q$ and $P E M A G$ in points 2 and 6. 


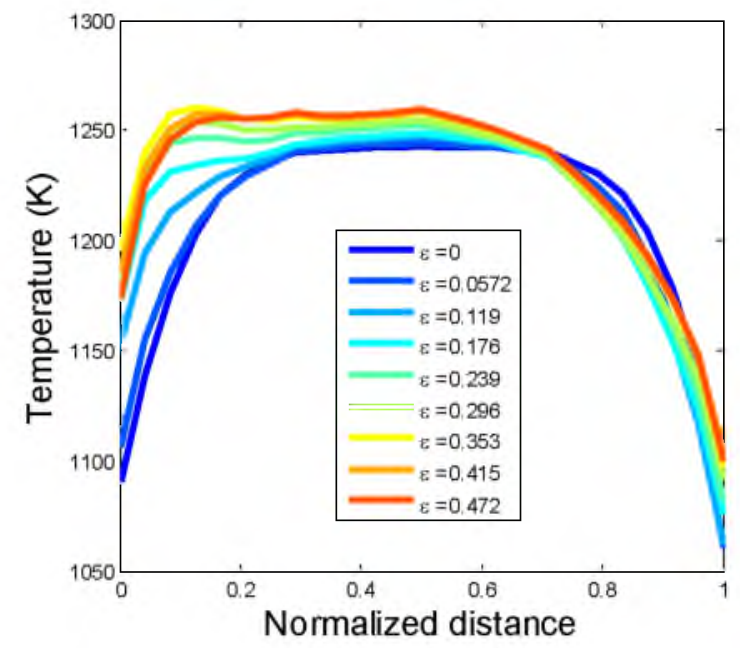

(a)

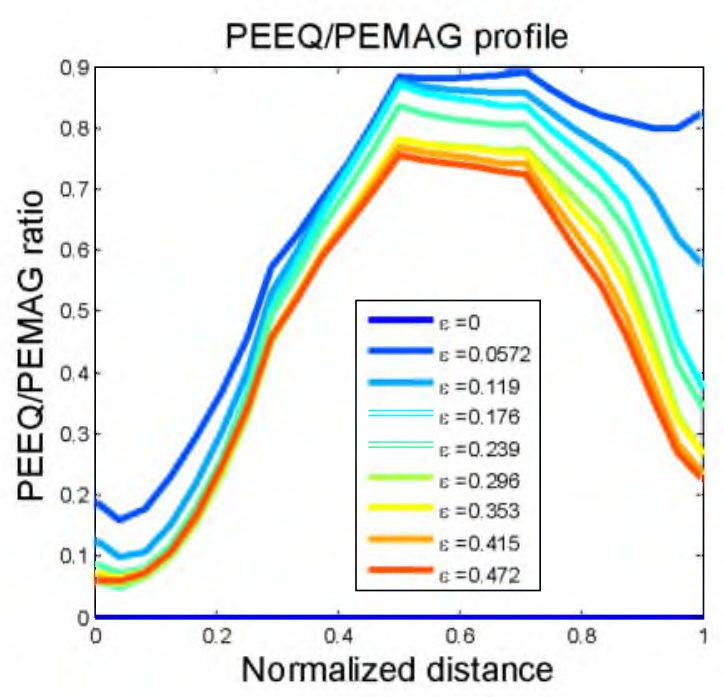

(b)

Figure 9. Ring-rolling with fixed thickness after $160 \mathrm{~s}$ of rolling (32 revolutions.). (a) Temperature $(\mathrm{K})$ profile along a diagonal of the ring section (distance convention: 0-upper corner, outer surface; 1-lower corner, inner surface). (b) Id., PEMAG/PEEQ ratio.

The patterns of equivalent strains and temperature are very different relative to the ring-rolling with allowance for free axial expansion. In particular, notice the very high values of the equivalent strain in the outer corners of the ring (fig. 8a) together with the corresponding rise of temperature in the outer half of the whole ring (fig 9a) and the very low value there of the ratio $P E E Q / P E M A G$, i.e., the dominance of strain reversal at that location.

\section{Discussion}

The two peculiarities of a typical 718 alloy ring-rolling operation of size and geometry of aeronautical interest, namely the delivery of the shape change by accumulation of a large number of very small strain steps and the large amount of strain reversal per revolution, make this process unique among other forming processes such as unidirectional rolling, forging or extrusion. It is, in many locations, an accumulation of small increments of unidirectional strain plus a superimposed low-cycle fatigue type deformation.

To our knowledge, all the simulations of ring-rolling published up to now (ours included) have been performed using constitutive equations obtained from monotonic tests (compression or torsion tests). We have not found any data of the constitutive behaviour of 718 alloy under either ratcheting or low-cycle fatigue conditions at temperatures as high as those required for hotworking (nor under conditions of a monotonic deformation with a superimposed cyclic one); however, available data for lower temperatures, of interest in aeroengine operation, show an important difference between monotonic and cyclic behaviour (e.g., significant LCF softening at $650^{\circ} \mathrm{C},[24-30]$ ). Consequently, we believe that a study of the constitutive behaviour of the 718 alloy in conditions close to those found in the industrial ring-rolling operation is worth being undertaken for attempting to optimize such a promising process. Such study is in progress. 


\section{Conclusions}

- Ring-rolling, so attractive for shaping 718 aeroengine parts, is a very peculiar hotworking process where the plastic deformation is imparted in small increments (of the order of a few percent). Moreover, the fraction of redundant strain (i.e., the degree of alternating strain cycles superimposed to the apparent shape change) is very high in many regions of the cross section of the ring.

- The structural and thermomechanical response of a material is known to be affected by such intermittencies and reversals of the plastic deformation with respect to the effects produced by a monotonic strain path. Their possible influence on the behaviour and structure of Superalloy 718 at temperatures and strain rates found in the ring-rolling process merits to be studied for establishing the optimal operation conditions.

\section{Acknowledgements}

The results presented in this paper have been obtained during the development of the project Rolled-Only IN718 Ring-shaped Components (RORC), CLEAN-SKY SP1-JTI-CS-2012-02 Grant agreement $n^{\circ} 325974$, European Union.

\section{References}

[1] W.A. Backofen, "Deformation Processing", Addison-Wesley, New York (1972)

[2] S.B. Davenport, R.L. Higginson, Strain path effects under hot-working: an introduction, J. Mater. Process. Technol., S.B., 98 (2000) 267.

[3] D. Jorge-Badiola, I. Gutierrez, Study of the strain reversal effect on the recrystallization and strain-induced precipitation in a Nb-microalloyed steel, Acta Mater., 52 (2004)333.

[4] L. Sun, K. Muszka, B.P. Wynne, E.J. Palmière, The effect of strain path reversal on highangle boundary formation by grain subdivision in a model austenitic steel, Scripta Mater., 64 (2010) 280.

[5] T. Lim, L. Pillinger, P. Hartley, A finite-element simulation of profile ring rolling using a hybrid mesh model, J. Mater. Proc. Technol., 80-81(1998)199.

[6] Y.K. Hu, W.K. Liu, ALE finite element formulation for ring rolling analysis, Int. J. Num. Methods Eng., 33(1992)1217.

[7] K. Davey, M.J. Ward, An efficient solution method for finite element ring-rolling simulation, Int. J. Num. Methods Eng., 47(2000)1997.

[8] K. Traoré, Simulation thermoméchanique du laminage circulaire. Développement d'une formulation quasi-eulérienne tridimensionnelle sur une architecture parallèle, Doctoral dissertation, ENSMP, France (2001).

[9] G. Losilla, P. Montmitonnet, M. Bouzaianne, P.E. Clément, Modélisation du laminage circulaire par éléments finis, Actes Conf. Matériaux, Tours (2002).

[10] D. Chabin, P. Y. Emptas, M. Bouzaiane, Numerical simulation of ring rolling process Application to superalloy 718 parts, AIP Conf. Proc. 907(2007)1366.

[11] J. Huez, J.L. Noyes, J. Coupu, Three-dimensional finite element simulation of hot ring Rolling, "Superalloys 718. 625. 706 and Various Derivatives", E. Loria, ed., The Minerals, Metals and Materials Society (2001), p. 249.

[12] J.-T. Yeom, J.H. Kim, N.-K. Park, S.S. Choi , C. S. Lee, Ring-rolling design for a largescale ring product of Ti-6Al-4V alloy, J. Mater. Proc. Technol., 187-188(2007)747. 
[13] Z. Sun, H. Yang, X. Ou, Thermo-mechanical coupled analysis of hot ring rolling process, Trans. Nonferrous Met. Soc. China, 18(2008)1216

[14] J.-T. Yeom, J.H. Kim, J.-K. Hong, N.-K. Park, C.S. Lee, FE Analysis of Microstructure Evolution during Ring Rolling Process of a Large-Scale Ti-6Al-4V Alloy Ring, Mater. Sci. Forum, 638-642(2010)223.

[15] J. Yeom, E. Jung, J. Kim, J. Hong, N. Park, K. Kim, J. Lee, and S. Choi, FE Simulation of Microstructure Evolution during Ring Rolling Process of INCONEL Alloy, Proc. $7^{\text {th }}$ Int. Symp "Superalloy 718 and Derivatives", p. 783, E.A. Ott, J.R. Groh, A. Banik, I. Dempster, T.P. Gabb, R. Helmink, X. Liu, A. Mitchell, G.P. Sjöberg, A. Wussatowska-Sarnek, eds., TMS, Wiley, New York (2010).

[16] Z.W. Wang, J.P.Fan, D.P.Hu, C.Y.Tang, C.P.Tsui, Complete modeling and parameter optimization for virtual ring rolling, Int J. Mech. Sci., 52(2010)1325.

[17] J. Zhou, F. Wang, M. Wang, W. Xu, Study on forming defects in the rolling process of large aluminum alloy ring via adaptive controlled simulation, Int. J. Adv. Manuf. Technol., $55(2011) 95$.

[18] L. Guo, H. Yang, Numerical Modelling and Simulation of

Radial-Axial Ring Rolling Process, Chapter $17^{\text {th }}$ in "Numerical Analysis. Theory and Application, J. Awrejcewicz, ed., In Tech, 2011.

[19] V. Jenkouk, G. Hirt, M. Franztke, T Zhang, Finite element modelling with integrated closed-loop control, CIRP Annals-Manufacturing Technology, 61(2012)267.

[20] Abaqus, Dassault Systèmes.

[21] H.Y. Zhang, S.H. Zhang, Z.X. Li, and M. Cheng, Hot die forging process optimization of superalloy IN718 turbine disk using processing map and finite element method, Proceedings of the Institution of Mechanical Engineers, Part B: Journal of Engineering Manufacture, 224(2010)103.

[22] G.A. Greene, C.C. Finfrock, T.F. Irvine Jr., Total hemispherical emissivity of oxidized Inconel 718 in the temperature range $300-1000^{\circ} \mathrm{C}$, Experimental Thermal and Fluid Science, $22(2000) 145$.

[23] J.L. Song, A.L. Dowson, M.H. Jacobs, J. Brooks, I. Beden, Coupled thermo-mechanical finite-element modeling of hot ring rolling process, J. Mater. Processing Technol., $121(2002) 332$.

[24] D. Fournier, A. Pineau, Low cycle behaviour of Inconel 718 at $298 \mathrm{~K}$ and $823 \mathrm{~K}$, Metall. Trans. A, 8A(1977)1095.

[25] M. Clavel, A. Pineau, Fatigue Behaviour of Two Nickel-base Alloys. I: Experimental Results on Low Cycle Fatigue, Fatigue Crack Propagation and Substructures, Mater. Sci. Eng., 55(1982)157.

[26] J.L. Chaboche, Modeling of the cyclic response and ratchetting e_ects on inconel-718 alloy, European Journal of Mechanics, A/Solids, 10(1991)101.

[27] F.Taina, M. Pasqualon, V. Velay, D.Delagnes, P. Lours, Effetc of the LCF loading cycle characteristics on the fatigue life of Inconel 718 at high temperature, Proc. $7^{\text {th }}$. Int. Symp. On Superalloy 718 and Derivatives, p. 893. E.A. Ott et al., eds., TMS, 2010.

[28] H. Kim, K.S. Kim, H. Park, Ratcheting behavior of Inconel 718 under multiaxial loading, J. Solid Mech. Mater. Eng., 4(2010)39.

[29] D. Gustafsson, J. J. Moverare, K. Simonsson, S. Sjöström, Modeling of the Constitutive Behavior of Inconel 718 at Intermediate Temperatures, J. Eng. Gas Turbines Power, 133(2011)094501.

[30] K. Prasad, R. Sarkar, P. Ghosal, V. Kumar, M. Sundararaman, High temperature low cycle fatigue deformation behaviour of forged IN 718 superalloy turbine disc, Mater. Sci. Eng. A, $568(2013) 239$. 